\title{
A CFD ASSESSMENT OF DRAG MODELS PERFORMANCE ON GAS-SOLID FLOW HYDRODYNAMICS IN A FLUIDIZED BED
}

\author{
C. M. R. LUNA ${ }^{1}$, I. ÁVILA ${ }^{1}$, L. R. CARROCCI ${ }^{1}$, G. L. A. F. ARCE ${ }^{2}$, \\ ${ }^{1}$ UNESP - Univ Estadual Paulista, Faculty of Engineering at Guaratinguetá, Department of Energy. \\ ${ }^{2}$ INPE - National Institute for Space Research \\ Email address: c_romeroluna@yahoo.com
}

\begin{abstract}
In this paper, a model based on the Eulerian-Eulerian approach considering the kinetic theory of granular flow (KTGF) is used in order to provide a comprehensive comparison between Gidaspow (1994) drag model and recent models found in literature, such as Hill et al. (2001), Yang et al. (2003), Zhang-Reese (2003), Van der Hoff et al. (2005) and Beetstra et al. (2007). The effects of these drag models on hydrodynamics behavior of gas-solid flow in fluidized bed will be investigated by using the MFIX code. The results are used to assess their capacity in predicting parameters such as pressure drop, bed expansion and voidage profiles, and then finally validated with the experimental results of Taghipour et al. (2005), which is available in literature. Results show that Hill et al. (2001), Zhang-Reese (2003) and Beetstra et al. (2007) drag models can be used to predict hydrodynamic parameters of gas-solid flow in a fluidized-bed much more accurately than Gidaspow (1994) model.
\end{abstract}

\section{INTRODUCTION}

Fluidized bed is an important unit operation of gas-solid contact, which has been widely used due to advantages, such as high rates of heat and mass transfer. Some of the major applications include fluid catalytic cracking (FCC), combustion, gasification, pyrolysis, among others. The performance of these applications depends mainly of knowledge of the gas-solid flow hydrodynamic, important in the design, operation and optimization of industrial scale units (Kunii and Levenspiel 1991; Gupta and Sathiyamoorthy 1999; Oka and Anthony 2004).

The modeling of gas-solid flow hydrodynamics in fluidized bed has been a topic of research for many years, resulting in significant progresses in this area (Lim, Zhu, and Grace 1995; Ranade 2001; Ahuja and Patwardhan 2008; M. a. van der Hoef et al. 2008). Nowadays, Computational Fluid Dynamics (CFD) has become a powerful tool in the study of gas-solid flow in fluidized bed (Li et al. 2009; Armstrong, Gu, and Luo 2010), as well as, to reduce time and cost complementing the industrial design of fluidized bed reactors (Ranade 2001; Min et al. 2010). There are two main approaches used in CFD modeling of gas-solid flow, Eulerian-Lagrangian approach, which is also referred to as the discrete particle model (DMP) and Eulerian-Eulerian approach, or also called as two-fluid model (TFM) (Deen, Van Sint Annaland, Van der Hoef, \& Kuipers, 2007; Vejahati, Mahinpey, Ellis, \& Nikoo, 2009). 


\section{9 a 22 de outubro de 2014 \\ Florianópolis/SC}

However, Eulerian-Eulerian approach is the most commonly used in CFD modeling of gassolid flow. In this approach the solid particles are modeled as a continuous medium, thereby, Kinetic Theory of Granular Flow (KTGF) is used to describe the stress tensor in the solid momentum equation, allowing a more realistic representation for particle-particle interactions, providing variables such as shear and bulk viscosity, as well as a solid pressure (Syamlal, Rogers, and O'Brien 1993; Reuge et al. 2008).

In Eulerian-Eulerian approach, the drag model is responsible for the hydrodynamic description, which have a strong influence on the spatial distribution of solid particles in fluidized bed, being very important in determining properties such as heat and mass transfer rates, thereby, the predictive accuracy of a CFD model depends on the drag model used to describe the drag force (Du, Bao, $\mathrm{Xu}, \&$ Wei, 2006; Sobieski, 2009; de Souza Braun et al. 2010; Esmaili and Mahinpey 2011).

Due to diverse applications of gas-solid flow, many drag models have been suggested in literature. Meanwhile, to get accurate simulated results, a drag model should be selected carefully. Several studies have been conducted based on suggested many drag models in order to identify which models most accurately predict gas-solid flow hydrodynamics in fluidized bed (Du et al., 2006; Vejahati et al., 2009; Esmaili \& Mahinpey, 2011; Loha, Chattopadhyay, \& Chatterjee, 2012;), however, there is no agreement among the various studies involving drag models.

Nevertheless, literature presents other drag models, such as Yang et al. (2003) and Zhang-Reese (2003) both based on Gidaspow (1994) drag model. These models present some considerable modifications in order to get a more approximate representation of gas-solid flow hydrodynamics. Yang et al. (2003) drag model, present a refinement in determining momentum transfer specifically when the gas-solid flow attains a dilute regime (Wang and Liu 2010; Loha, Chattopadhyay, and Chatterjee 2012). Zhang-Reese (2003) have developed a more sensitive drag model, taking into account the velocity fluctuation of solid particles in the flow by the inclusion of granular temperature (Halvorsen 2005; Vejahati et al. 2009; Esmaili and Mahinpey 2011). Moreover, literature presents drag models obtained by direct numerical simulation technique - the Lattice Boltzmann simulation technique, such as Hill et al. (2001), van der Hoef et al. (2005) and Beetstra et al. (2007).

Despite published studies about drag models, only limited studies present an evaluation of drag models aforementioned. The objective of this paper is to evaluate the performance of these drag models, in order to obtain a better representation of gas-solid flow hydrodynamics in a fluidized-bed through the capability in predicting design parameters such as pressure drop, bed expansion and voidage profiles. A CFD model based on Eulerian-Eulerian approach in combination with KTGF was used. The results are validate using the experimental data of Taghipour et al. (2005).

\section{HYDRODYNAMIC MODEL}

Eulerian-Eulerian approach considers each of the phases to be interpenetrating and continuum, and the governing equations of mass, momentum and energy conservations are solved for each of the phases which are local mean averages of the fluid point and particles variables (Ahuja \& Patwardhan, 2008). 


\subsection{Governing Equations}

Regarding an isothermal gas-solid flow without chemical reactions, the conservation equations for mass and momentum balance can be written as:

$$
\begin{aligned}
& \frac{\partial}{\partial t}\left(\alpha_{g} \rho_{g}\right)+\nabla\left(\alpha_{g} \rho_{g} u_{g}\right)=0 \\
& \frac{\partial}{\partial t}\left(\alpha_{s} \rho_{s}\right)+\nabla\left(\alpha_{s} \rho_{s} u_{s}\right)=0 \\
& \frac{\partial}{\partial t}\left(\alpha_{g} \rho_{g} u_{g}\right)+\nabla\left(\alpha_{g} \rho_{g} u_{g} u_{g}\right)=\nabla \bar{\sigma}_{g}+\alpha_{g} \rho_{g} \vec{g}-F_{D} \\
& \frac{\partial}{\partial t}\left(\alpha_{s} \rho_{s} u_{s}\right)+\nabla\left(\alpha_{s} \rho_{s} u_{s} u_{s}\right)=-\alpha_{s} \nabla p_{g}-\nabla \bar{\sigma}_{s}+\alpha_{s} \rho_{s} \vec{g}+F_{D}
\end{aligned}
$$

Under regime dense flow conditions, the gas-phase turbulent stresses could be neglected without any noticeable effect on the time-averaged flow profiles (Lindborg, Lysberg, \& Jakobsen, 2007). For the gas phase, the stress tensor and shear stress are given by equations (5) and (6), respectively:

$$
\begin{aligned}
& \bar{\sigma}_{g}=-p_{g} \overline{\bar{I}}+\nabla \alpha_{g} \tau_{g} \\
& \bar{\tau}_{g}=\mu_{g}\left[\nabla \vec{v}_{g}+\left(\nabla \vec{v}_{g}\right)^{T}-\frac{2}{3} \nabla \cdot \vec{v}_{g} \overline{\bar{I}}\right]
\end{aligned}
$$

For the solid phase, Syamlal et al. (1993) has formulated a solid phase stress tensor combining the KTGF of Jenkins and Savage (1983) with the critical state theory of Schaeffer (1987). The combination of both theories for viscous (dilute) and plastic (dense) flow regimes was applied to investigate the behavior of solid particles, respectively, leading to the following relations for computing the solid phase stress constitutive equations, represented as:

$$
\overline{\bar{\sigma}}_{s}=\left\{\begin{array}{c}
-p_{s}^{p} \overline{\bar{I}}+\bar{\tau}_{s} \\
-p_{s}^{v} \overline{\bar{I}}+\alpha_{s} \leq \alpha_{g} \leq \alpha_{g}^{*}
\end{array}\right.
$$

where, the superscripts (p) and (v) represent plastic and viscous regimes respectively, and $\alpha_{g}^{*}$ is the initial voidage in the bed. The solid phase stresses tensor in the plastic flow regime is described by theories from the study of solid mechanics. The solid phase pressure in a plastic regime is determined by: 


$$
p_{s}^{p}=\alpha_{s} p^{*}
$$
$n=10$

where, $p^{*}$ is represented by an empirical power law with typical values of $A=10^{25}$ and

$$
p^{*}=\alpha_{s} A\left(\alpha_{g}^{*}-\alpha_{g}\right)^{n}
$$

The solid phase shear stress in the plastic regime is calculated as:

$$
\stackrel{=p}{\tau_{s}}=2 \mu_{s}^{p} \overline{\bar{D}}_{s}
$$

where, ${ }^{p}$ is the solid phase dynamic viscosity in the plastic regime

$$
\mu_{s}^{p}=\frac{p^{*} \sin \Phi}{2 \sqrt{I_{2 D}}}
$$

where, $\Phi$ is an angle of internal friction and $I_{2 D}$ represents the second invariant of the deviator of the strain rate tensor $D_{s}$, is given by:

$$
I_{2 \mathrm{D}}=\frac{1}{6}\left[\left(D_{s 11}-D_{s 22}\right)^{2}+\left(D_{s 22}-D_{s 33}\right)^{2}+\left(D_{s 33}-D_{s 11}\right)^{2}\right]+D_{s 12}^{2}+D_{s 23}^{2}+D_{s 31}^{2}
$$

The solid phase stresses tensor in the viscous regime is calculated using KTGF. Solid physical properties such as, $p_{s}^{v}, \mu_{s}^{v}, \lambda_{s}^{v}$ are determined as a function of granular temperature $\theta$ s, represented as:

$$
\begin{aligned}
& p_{s}^{v}=K_{1} \alpha_{s}^{2} \theta_{s} \\
& \left.\stackrel{=}{\tau_{s}}=2 \mu_{s}^{v} \overline{\bar{D}}_{s}+\lambda_{s}^{v} \operatorname{tr} \overline{\bar{D}}_{s}\right) \overline{\bar{I}}
\end{aligned}
$$

where, $\mu_{s}^{v}$ and $\lambda_{s}^{v}$ is the solid phase dynamic and volumetric viscosities in the viscous regime, respectively, expressed by:

$$
\mu_{s}^{v}=K_{3} \alpha_{s} \sqrt{\theta_{s}}
$$




$$
\lambda_{s}^{v}=K_{2} \alpha_{s} \sqrt{\theta_{s}}
$$

In this work, the algebraic granular temperature equation was used. According to Syamlal et al. (1993), this allows the possibility of convergence acceleration by directly computing the granular temperature through a simple algebraic expression, instead of solving a complex partial differential equation (PDE). The algebraic granular temperature equation can be reasonably used without diminishing its accuracy only when the gas-solid flow has higher values of solid volumetric fraction and lower values of solid velocity, such as in a dense regime (Hosseini, Zhong, Esfahany, Pourjafar, \& Azizi, 2010; van Wachem, Schouten, van den Bleek, Krishna, \& Sinclair, 2001). The algebraic granular temperature equation is represented as:

$$
\theta_{s}=\left\{\frac{-K_{1} \alpha_{s} \operatorname{tr}\left(\overline{\bar{D}}_{s}\right)+\sqrt{K_{1}^{2} t r^{2}\left(\overline{\bar{D}}_{s}\right) \alpha_{s}^{2}+4 \mathrm{~K}_{4} \alpha_{s}\left[K_{2} t r^{2}\left(\overline{\bar{D}}_{s}\right)+2 \mathrm{~K}_{3} t r^{2}\left(\overline{\bar{D}}_{s}\right)\right]}}{2 \mathrm{~K}_{4} \alpha_{s}}\right\}^{2}
$$

where, $\mathrm{K}_{1}, \mathrm{~K}_{2}, \mathrm{~K}_{3}$ and $\mathrm{K}_{4}$ are defined as:

$$
\begin{aligned}
& K_{1}=2(1+e) \rho_{s} g_{0} \\
& K_{2}=\frac{4 \mathrm{~d}_{s} \rho_{s}(1+e) \alpha_{s} g_{0}}{3 \sqrt{\pi}}-\frac{2}{3} K_{3} \\
& K_{3}=\frac{d_{s} \rho_{s}}{2}\left\{\frac{\sqrt{\pi}}{3(3-e)}\left[1+0,4(1+e)(3 e-1) \alpha_{s} g_{0}\right]+\frac{8 \alpha_{s} g_{0}(1+e)}{5 \sqrt{\pi}}\right\} \\
& K_{4}=\frac{12\left(1-e^{2}\right) \rho_{s} g_{0}}{d_{s} \sqrt{\pi}}
\end{aligned}
$$

where, e is the restitution coefficient, this variable represent the collisions of solid particles, and g0 is the radial distribution function in contact with solid particles. MFIX code uses by default Carnahan and Starling (1969) radial distribution function defined as:

$$
g_{0}=\frac{1}{\alpha_{g}}+\frac{1,5 \alpha_{g}}{\alpha_{g}^{2}}
$$

\subsection{Drag model $(\beta)$}

The drag force in gas-solid flow is determinate by the product of a drag model $\left(\beta_{\mathrm{gs}}\right)$ and the relative velocity (ug - us) between both phases, represented as: 


$$
F_{D}=\beta_{g s}\left(u_{g}-u_{s}\right)
$$

The drag model, as called interphase momentum exchange coefficient, is an important parameter in gas-solid interaction modeling. This parameter allows determining the momentum transfer between the gas and solid phases. The description of the gas-solid flow moment transfer through the drag model is very important, since fluidization is a result of the drag exerted by the interfacial gas flow in the gap between the solid particles (Ahuja \& Patwardhan, 2008; de Souza Braun et al., 2010).

Gidaspow (1994) model

$$
\begin{aligned}
& \beta_{\text {Ergun }}=150 \frac{\alpha_{s}^{2} \mu_{g}}{\alpha_{g} d_{s}^{2}}+1.75 \frac{\alpha_{s} \rho_{g}\left|u_{g}-u_{s}\right|}{d_{s}}, \quad \alpha_{g}<0.8 \\
& \beta_{W e n-Y u}=\frac{3}{4} C_{D} \frac{\alpha_{s} \alpha_{g} \rho_{g}\left|u_{g}-u_{s}\right|}{d_{s}} \alpha_{g}^{-2.65}, \quad \alpha_{g}>0.8 \\
& C_{D}= \begin{cases}\frac{24}{\alpha_{g} \operatorname{Re}_{s}}\left[1+0.15\left(\alpha_{g} \operatorname{Re}_{s}\right)^{0.687}\right] & \operatorname{Re}_{s} \leq 1000 \\
0.44 & \operatorname{Re}_{s}>1000\end{cases} \\
& \operatorname{Re}_{s}=\frac{\rho_{g}\left|u_{g}-u_{s}\right| d_{s}}{\mu_{g}}
\end{aligned}
$$

Hill et al. (2001) model

$$
\beta_{g s}=18 \mu_{g}\left(1-\alpha_{s}\right)^{2} \alpha_{s} \frac{F}{d_{s}^{2}}
$$

The force $\mathrm{F}$ is defined as:

$$
\begin{aligned}
& F=1+3 / 8 \operatorname{Re}_{s} \quad \alpha_{s} \leq 0.01 \text { and } \operatorname{Re}_{s} \leq\left(F_{2}-1\right) /(3 / 8)-F_{3} \\
& F=F_{0}+F_{1} \operatorname{Re}_{s}^{2} \quad \alpha_{s}>0.01 \text { and } \operatorname{Re}_{s} \leq F_{3}+\sqrt{F_{3}^{2}-4 \mathrm{~F}_{1}\left(F_{0}-F_{2}\right)} / 2 \mathrm{~F}_{1} \\
& F=F_{2}+F_{3} \operatorname{Re}_{s}\left\{\begin{array}{ccc}
\alpha_{s} \leq 0.01 & \text { and } & \operatorname{Re}_{s}>\left(F_{2}-1\right) /(3 / 8)-F_{3} \\
\alpha_{s}>0.01 & \text { and } & \operatorname{Re}_{s}>F_{3}+\sqrt{F_{3}^{2}-4 \mathrm{~F}_{1}\left(F_{0}-F_{2}\right)} / 2 \mathrm{~F}_{1}
\end{array}\right.
\end{aligned}
$$


where parameters are defined as follows:

$$
F_{0}=\left\{\begin{array}{l}
(1-w)\left[\frac{1+3 \sqrt{\alpha_{s} / 2}+(135 / 64) \alpha_{s} \ln \left(\alpha_{s}\right)+17.41 \alpha_{s}}{1+0.681 \alpha_{s}-8.4 \alpha_{s}^{2}+8.16 \alpha_{s}^{3}}\right]+w\left[10 \alpha_{s} /\left(1-\alpha_{s}\right)^{3}\right] 0.01<\alpha_{s}<0.4 \\
\frac{10 \alpha_{s}}{\left(1-\alpha_{s}\right)^{3}} \quad \alpha_{s}>0.4
\end{array}\right.
$$

$$
F_{1}=\left\{\begin{array}{lc}
\frac{\sqrt{\left(2 / \alpha_{s}\right)}}{40} & 0.01<\alpha_{s} \leq 0.1 \\
0.11+0.00051 e^{\left(11.6 \alpha_{s}\right)} & \alpha_{s}>0.1
\end{array}\right.
$$$$
F_{2}=\left\{\begin{array}{l}
(1-w)\left[\frac{1+3 \sqrt{\alpha_{s} / 2}+(135 / 64) \alpha_{s} \ln \left(\alpha_{s}\right)+17.89 \alpha_{s}}{1+0.681 \alpha_{s}-11.03 \alpha_{s}^{2}+15.41 \alpha_{s}^{3}}\right]+w\left[10 \alpha_{s} /\left(1-\alpha_{s}\right)^{3}\right] \alpha_{s}<0.4 \\
\frac{10 \alpha_{s}}{\left(1-\alpha_{s}\right)^{3}} \quad \alpha_{s} \geq 0.4
\end{array}\right.
$$

$$
F_{3}= \begin{cases}0.9351 \alpha_{s}+0.03667, & \alpha_{s}<0.0953 \\ 0.0673+0.212 \alpha_{s}+0.0232 /\left(1-\alpha_{s}\right)^{5}, & \alpha_{s} \geq 0.0953\end{cases}
$$

$\operatorname{Re}_{s}=\frac{\rho_{\mathrm{g}} d_{s}\left(1-\alpha_{\mathrm{s}}\right)\left|u_{g}-u_{s}\right|}{2 \mu_{g}}$

$$
w=e^{\left(-10\left(0.4-\alpha_{s}\right) / \alpha_{s}\right)}
$$

Yan et al. (2003) model

$$
\begin{aligned}
& \beta_{g s}=150 \frac{\alpha_{s}^{2} \mu_{g}}{\alpha_{g} d_{s}^{2}}+1.75 \frac{\alpha_{s} \rho_{g}\left|u_{g}-u_{s}\right|}{d_{s}}, \quad \alpha_{g}<0.74 \\
& \beta_{g s}=\frac{3}{4} C_{D} \frac{\alpha_{s} \alpha_{g} \rho_{g}\left|u_{g}-u_{s}\right|}{d_{s}} \omega\left(\alpha_{g}\right), \quad \alpha_{g} \geq 0.74
\end{aligned}
$$


where the values for $\omega\left(\alpha_{g}\right)$ are given by:

$$
\begin{aligned}
& \omega\left(\alpha_{g}\right)= \begin{cases}-0.5760+\frac{0.0214}{4\left(\alpha_{g}-0.7463\right)^{2}+0.0044}, & 0.74<\alpha_{g} \leq 0.82 \\
-0.0101+\frac{0.0038}{4\left(\alpha_{g}-0.7789\right)^{2}+0.0040}, & 0.82<\alpha_{g} \leq 0.97 \\
-31.8295+32.8295 \alpha_{g}, \quad \alpha_{g}>0.97\end{cases} \\
& C_{D}=\left\{\begin{array}{l}
\frac{24}{\alpha_{g} \operatorname{Re}_{s}}\left[1+0.15\left(\alpha_{g} \operatorname{Re}_{s}\right)^{0.687}\right] \operatorname{Re}_{s} \leq 1000 \\
0.44 \quad \operatorname{Re}_{s}>1000
\end{array}\right. \\
& \operatorname{Re}_{s}=\frac{\rho_{g}\left|u_{g}-u_{s}\right| d_{s}}{\mu_{g}}
\end{aligned}
$$

Zhang-Reese (2003) model

$$
\begin{aligned}
& \beta_{g s}=150 \frac{\alpha_{s}^{2} \mu_{g}}{\alpha_{g} d_{s}^{2}}+1.75 \frac{\alpha_{s} \rho_{g}}{d_{s}} U_{r}, \quad \alpha_{g}<0.8 \\
& \beta_{g s}=\frac{3}{4} C_{D} \frac{\alpha_{s} \rho_{g}}{d_{s}} U_{r} \alpha_{g}^{-2,65}, \quad \alpha_{g}>0.8 \\
& U_{r}=\left[\left(u_{s}-u_{g}\right)^{2}+\frac{8 \theta_{s}}{\pi}\right]^{1 / 2} \\
& C_{D}=\left(0.28+\frac{6}{\sqrt{\operatorname{Re}_{s}}}+\frac{21}{\operatorname{Re}_{s}}\right) \\
& \operatorname{Re}_{s}=\frac{\rho_{g} U_{r} d_{s}}{\mu_{g}}
\end{aligned}
$$

Van de Hoef et al. (2005) model 
$\beta_{g s}=\frac{18 \mu_{g}\left(1-\alpha_{s}\right)^{2} \alpha_{s}}{d_{s}^{2}}\left(F_{0}\left(\alpha_{s}\right)+F_{1}\left(\alpha_{s}\right) \operatorname{Re}_{s}\right)$

where the dimensionless coefficients $F_{0}\left(\alpha_{s}\right), F_{1}\left(\alpha_{s}\right)$ and $\operatorname{Re}_{s}$ are defined as:

$$
\begin{aligned}
& F_{0}\left(\alpha_{s}\right)=10 \frac{\alpha_{s}}{\left(1-\alpha_{s}\right)^{2}}+\left(1-\alpha_{s}\right)^{2}\left(1+1.5 \sqrt{\alpha_{s}}\right) \\
& F_{1}\left(\alpha_{s}\right)=\frac{0.48+1.9 \alpha_{s}}{18\left(1-\alpha_{s}\right)^{2}} \\
& \operatorname{Re}_{s}=\frac{\rho_{g}\left|u_{g}-u_{s}\right| d_{s}}{\mu_{g}}
\end{aligned}
$$

Beetstra et al. (2007) model

$$
\beta_{g s}=\frac{18 \mu_{g}\left(1-\alpha_{s}\right)^{2} \alpha_{s}}{d_{s}^{2}} F_{0}
$$

where $F_{0}$ has the form:

$$
F_{0}=10 \frac{\alpha_{s}}{\left(1-\alpha_{s}\right)^{2}}+\left(1-\alpha_{s}\right)^{2}\left(1+1.5 \sqrt{\alpha_{s}}\right)+\frac{0.413 \operatorname{Re}_{s}}{24\left(1-\alpha_{s}\right)^{2}}\left[\frac{\left(1-\alpha_{s}\right)^{-1}+3 \alpha_{s}\left(1-\alpha_{s}\right)+8.4 \operatorname{Re}_{s}^{-0.343}}{1+10^{3 \alpha_{s}} \operatorname{Re}_{s}^{-\left(1+4 \alpha_{s}\right) / 2}}\right]
$$

\section{NUMERICAL SOLUTION PROCEDURE}

The CFD open source, code MFIX version 2012-1, was used to carry out a set of simulations in a 2D gas-solid fluidized bed in a Cartesian framework represented in Fig. 1. According to Hosseini et al. (2010) to use a two-dimensional model reduce the computational time while maintaining accuracy. Drag models such as Yang et al. (2003), Zhang-Reese (2003) and van der Hoef et al. (2005) were implemented in the MFIX code. The simulations are performed for a time period of 25 seconds, in order to eliminate the large temporal fluctuation of all variables, thereby the time-averaging was done between $5-25$ seconds in real-time simulation. 


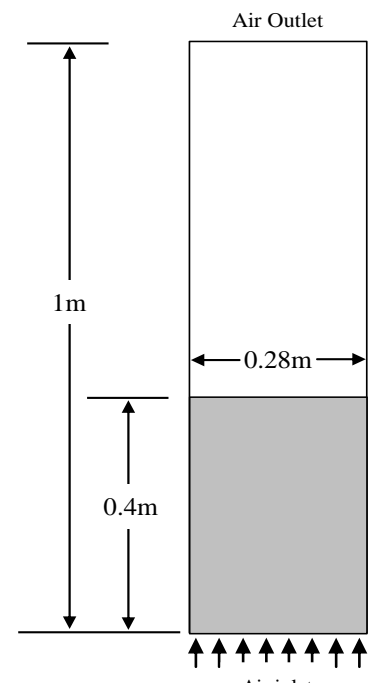

Air inlet

Figure 1 - Schematic of 2D fluidized bed (Taghipour, Ellis, \& Wong, 2005)

For the convective terms discretization, SUPERBEE scheme can be used to simulate a gassolid fluidized bed in a course grid in order to avoid numerical diffusion effects (de Souza Braun et al., 2010; Hosseini, Ahmadi, Saeedi Razavi, \& Zhong, 2010). The vertical sidewalls were treated with no-slip boundary conditions, while the base and top had fixed velocity inflow and pressure outflow boundary conditions. A fixed time step in the 10-5 order of magnitude is sufficient to avoid the instability in convergence for 2D multiphase simulations. Based on grid independence studies (Esmaili \& Mahinpey, 2011; Vejahati et al., 2009), a uniform square grid size of $0.005 \mathrm{~m}$ was used. The operating conditions and solid properties used on the experimental setup by Taghipour et al. (2005) are summarized in Table 1.

Table 1 - Properties of the gas and solid phases

\begin{tabular}{ll}
\hline Bed width & $0.28 \mathrm{~m}$ \\
Bed height & $1 \mathrm{~m}$ \\
Static bed height & $0.4 \mathrm{~m}$ \\
Particle density (glass beads) & $2500 \mathrm{~kg} / \mathrm{m}^{3}$ \\
Mean particle diameter & $275 \mu \mathrm{m}$ \\
Initial solids packing & 0.6 \\
Restitution coefficient & 0.9 \\
Air density & $1.225 \mathrm{~kg} / \mathrm{m}^{3}$ \\
Air viscosity & $1.8 \times 10^{-5} \mathrm{~kg} / \mathrm{m} . \mathrm{s}$ \\
Range of gas velocity & $0.025-0.50 \mathrm{~m} / \mathrm{s}$ \\
Minimum fluidization velocity & $0.065 \mathrm{~m} / \mathrm{s}$ \\
Voidage at minimum fluidization & 0.5 \\
\hline
\end{tabular}




\section{RESULTS AND DISCUSSIONS}

In this study, to perform the numerical simulations, it was defined ten gas velocities $(0.025$, $0.065,0.10,0.15,0.20,0.30,0.38,0.40,0.46$ and $0.51 \mathrm{~m} / \mathrm{s})$. Experimentally data of Taghipour et al. (2005) are pressure drop, bed expansion and voidage profiles, the latter was measured at $0.2 \mathrm{~m}$ above the distributor at a gas velocity of 0.38 and $0.46 \mathrm{~m} / \mathrm{s}$, respectively. According to Hosseini et al. (2010) and Behjat et al (2008), in order to quantitatively assess the profiles obtained by numerical simulations, the root mean square deviations (RMSD) can be used, represented as:

$$
\delta_{R M S D}=\left[\frac{1}{N} \sum_{1}^{N}\left(\frac{V_{\text {exp }}-V_{\text {num }}}{V_{\text {exp }}}\right)^{2}\right]^{1 / 2} \times 100
$$

\subsection{Pressure Drop}

Figure 2 shows the pressure drop inside the bed as a function of gas velocity. The pressure drop predicted using drag models present a similar trend to the experimental data. The pressure drop attains a maximum value remaining nearly constant as gas velocity increases, this behavior agrees qualitatively with the experimental data. Gidaspow (1994), Hill et al. (2001), Zhang-Reese (2003) and Beetstra et al. (2007) models show the same trend and predict almost the same values of pressure drop, reaching an almost constant value at experimental minimum fluidization velocity $(0.065 \mathrm{~m} / \mathrm{s})$, nevertheless, the value of pressure drop is overestimated when compared with the experimental value (4400 Pa). This difference is due to the simulation was considered that a system with constant particle diameter and the experimental data exhibit a characteristic behavior of systems with a large particle size distribution, mainly affecting the pressure drop in the bed. Yang et al. (2003) and van der Hoef et al. (2005) drag models present a significant difference in the prediction of pressure drop, initially underestimated until reached a gas velocity above the minimum fluidization, beginning a state of fluidization.

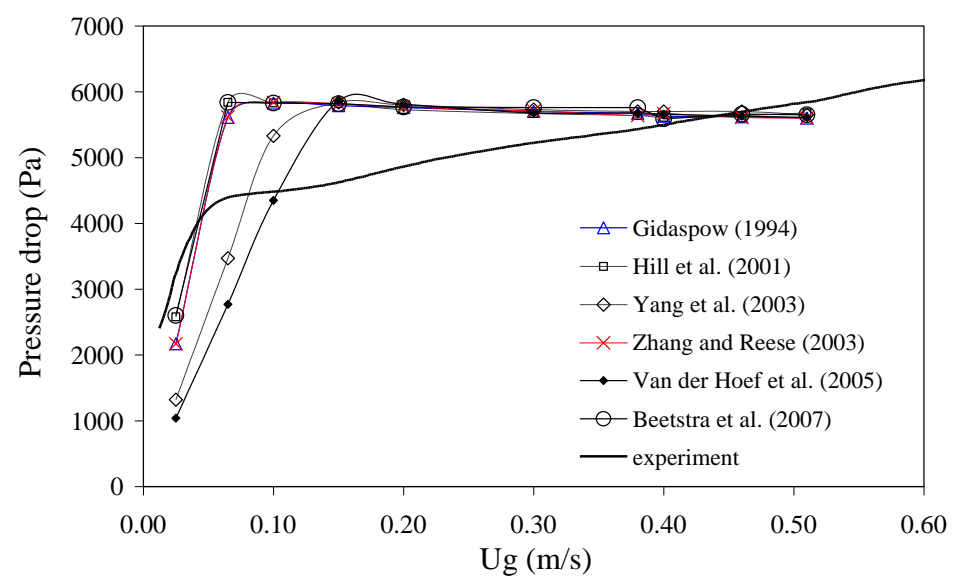

Figure 2 - Pressure drop in function of gas velocity. 


\subsection{Bed Expansion}

Figure 3 compare the time-averaged bed expansion obtained with each drag model. The timeaveraged bed expansion was determined following the procedure of Lindborg et al. (2007). All simulations agrees qualitatively with the experimental data. At low velocities $(0.025 \mathrm{~m} / \mathrm{s})$ and minimum fluidization velocity $(0.065 \mathrm{~m} / \mathrm{s})$ the results do not show a bed expansion.It is observed that Gidaspow (1994), Hill et al. (2001), Zhang-Reese (2003) and Beetstra et al. (2007) models predict suitable bed expansion at a gas velocity of $0.10 \mathrm{~m} / \mathrm{s}$, indicating a fluidization state, while Yang et al. (2003) and van der Hoef et al. (2005) models do not predict bed expansion, exhibiting still a fixed bed state. At gas velocities in the range of $0.15-0.30 \mathrm{~m} / \mathrm{s}$, Gidaspow (1994), Hill et al. (2001), ZhangReese (2003) and Beetstra et al. (2007) models have a similar predictive values, which agree quantitatively with experimental data. Yang et al. (2003) and van der Hoef et al. (2005) models underestimate the bed expansion, however, according the gas velocity increases the underestimation is considerably reduced. Thereby, as it can be seen in a Fig. 3, at gas velocities of 0.38 and $0.46 \mathrm{~m} / \mathrm{s}$, respectively, their prediction quantitatively well agree with the experimental data. At gas velocities of 0.38 and 0.46 m/s, Gidaspow (1994), Hill et al. (2001), Zhang-Reese (2003) and Beetstra et al. (2007) models slightly overestimate the bed expansion, and this trend continues as gas velocity increases.

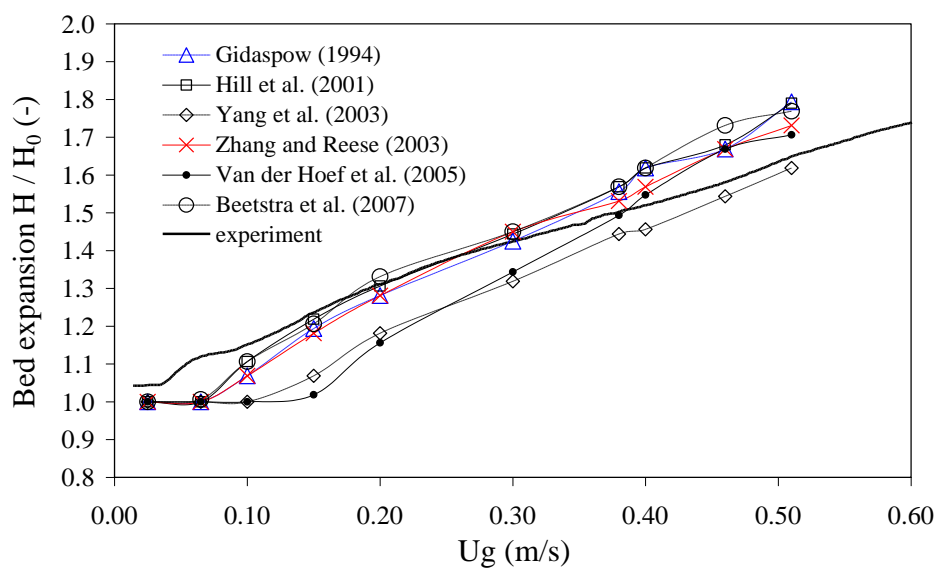

Figure 3 - Comparison between the simulated bed expansion for different drag models.

\subsection{Time-averaged voidage profile}

Figures 4 and 5 show time-averaged local voidage profiles obtained with each drag model. Analyzing the experimental data of Taghipour et al. (2005), it is noted that according to the gas velocity increases, the experimental voidage profile tends to develop greater uniformity. Timeaveraged voidage profiles present two zones, the central and near to wall zone, where there are high and low values of voidage, respectively. As it can be observed in Figures 4 and 5, the voidage profiles predicted by the drag models present a similar behavior, some drag models overestimate the value of voidage profiles, specifically in the central part of the bed. However, the predicted value will be gradually reduced, as it becomes closer to the experimental value, as the profile extends on the sides 
of the bed. In Figure 4 the voidage profiles obtained at a gas velocity of $0.38 \mathrm{~m} / \mathrm{s}$ are very irregular, however, in Fig. 5, the voidage profile obtained by Gidaspow (1994), Hill et al. (2001) and Beetstra et al. (2007) models display a more uniform profile keeping nearly the same behavior. This behavior is due to the presence of bubble, at low gas velocity, there are small bubbles which inducing a irregular profile, however, as gas velocity increases, the bubble size increase causing a more profile more uniform. Yang et al. (2003) and van der Hoef et al. (2005) models produce voidage profiles qualitatively more approximated with the experimental data in both gas velocities $(0.38$ and $0.46 \mathrm{~m} / \mathrm{s})$.

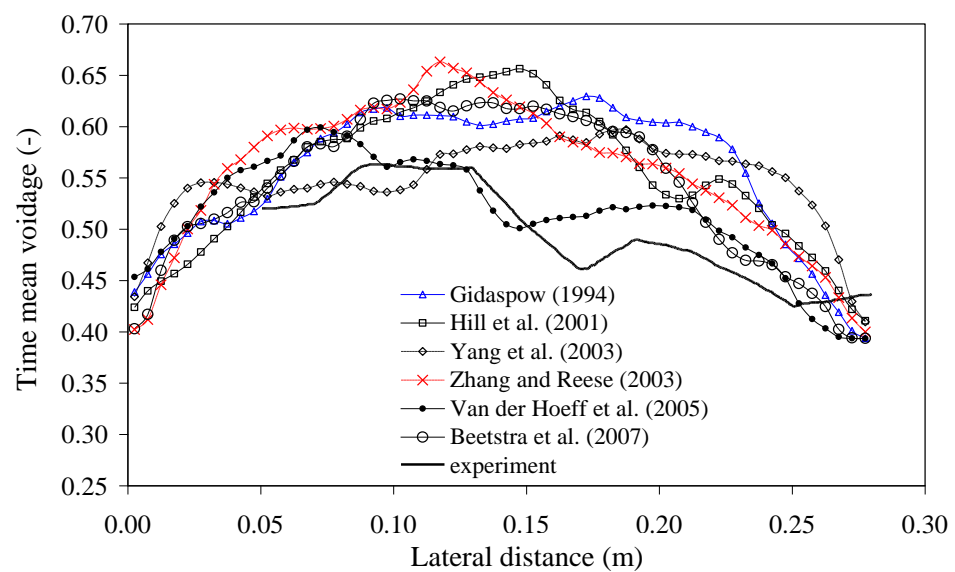

Figure 4 - Time-averaged local voidage profiles at $\mathrm{Ug}=0.38 \mathrm{~m} / \mathrm{s}$.

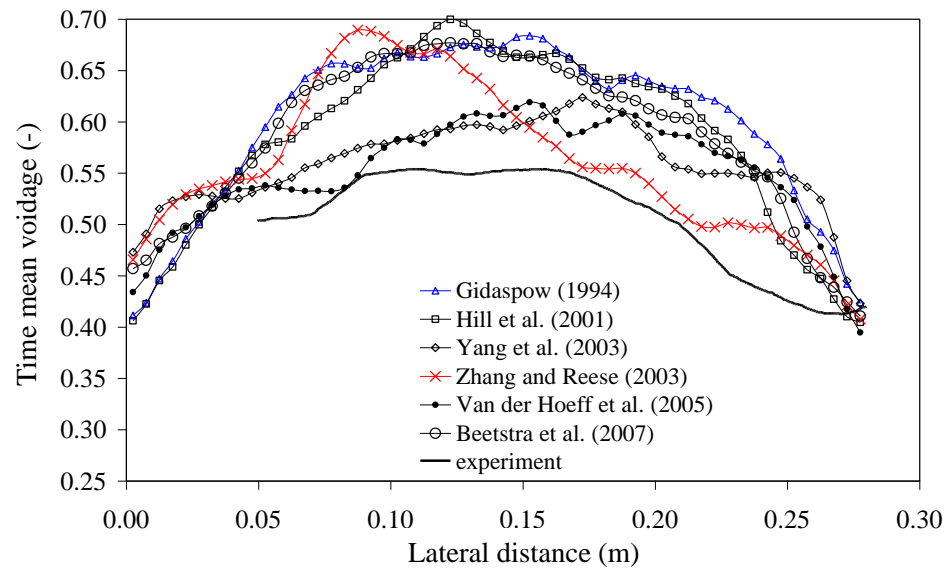

Figure 5 - Time-averaged local voidage profiles at $\mathrm{Ug}=0.46 \mathrm{~m} / \mathrm{s}$.

\subsection{Statistical Analysis}

Table 2 shows a statistical analysis that is made to the profiles obtained by numerical simulation with each drag model. The results show that Hill et al. (2001) drag model can determine the pressure drop fairly well, in opposite, Yang et al. (2003) and van der Hoef et al. (2005) drag models present higher values of RMSD, due to their initial underestimation, as shown in Fig. 2. 
According to Table 2, in the prediction of bed expansion, Zhang-Reese (2003) model presents the most favorable prediction, following by Hill et al. (2001). The prediction of voidage profiles exhibit higher values of RMSD. This parameter is most difficult to analyze due to its temporal variation. At gas velocities of 0.38 and $0.46 \mathrm{~m} / \mathrm{s}$, van der Hoef et al. (2005) drag model presents the most favorable prediction. This result does not define this as the most appropriate model to be used in CFD simulations, since its performance is not consistent at the time of predicting pressure drop and bed expansion.

Table 2 - RMS Deviations

\begin{tabular}{ccccc}
\hline Drag model & \multirow{2}{*}{$\mathrm{H}$} & $\mathrm{H} / \mathrm{H}_{0}$ & $\begin{array}{c}\text { Local voidage } \\
\mathrm{Ug}=0.38 \mathrm{~m} / \mathrm{s}\end{array}$ & $\begin{array}{c}\text { Local voidage } \\
\mathrm{Ug}=0.46 \mathrm{~m} / \mathrm{s}\end{array}$ \\
\hline (Gidaspow, 1994) & 19.57 & 6.02 & 18.68 & 23.71 \\
(Hill, Koch, \& Ladd, 2001) & 18.59 & 5.70 & 17.22 & 20.06 \\
(Yang, 2003) & 23.44 & 8.24 & 16.66 & 14.32 \\
(Zhang \& Reese, 2003) & 19.74 & 5.31 & 15.76 & 14.79 \\
(M. Van der Hoef, Beetstra, \& Kuipers, 2005) & 26.80 & 9.12 & 7.20 & 13.74 \\
(Beetstra, Hoef, \& Kuipers, 2007) & 18.76 & 5.95 & 15.02 & 20.01 \\
\hline
\end{tabular}

\section{CONCLUSSIONS}

In this study, it was developed an assessment of drag models founded in literature. The MFIX code was used to solve the model CFD based in Eulerian-Eulerian approach to represent the gas-solid flow hydrodynamic behavior in a two-dimensional fluidized bed. The present work showed a good agreement with the numerical results and the experimental data from Taghipour et al.(2005).

From statistic analysis, Zhang-Reese (2003), Hill et al. (2001) and Beetstra et al. (2007) drag models can be used to predict hydrodynamic parameters of gas-solid flow in a fluidized bed, being much more accurately than Gidaspow (1994) model, commonly used and many works involving CFD. Thus, can be concluded that drag models derived of Lattice Boltzmann simulation can provide a more accurate representation of gas-solid flow hydrodynamics in fluidized-bed. Due to changes in its formulation, Yang et al. (2003) drag model is not suitable to represent fluidized beds in bubbling regime.

According to the results, it can be said that the pressure drop and bed expansion are the most feasible design parameters to be determined, in addition, it is possible to estimate the minimum fluidization velocity through numerical simulations. Nevertheless, no drag model properly represented expansion of the minimum bed fluidization and the voidage profile is the most difficult and sensitive variable to predict. With the RMSD results, It can be concluded that the performance of drag model is on the basis of gas velocity range in which it is going to be utilized. 


\section{REFERÊNCIAS}

Ahuja, G. N., \& Patwardhan, A. W. (2008). CFD and experimental studies of solids hold-up distribution and circulation patterns in gas - solid fluidized beds, 143, 147-160. doi:10.1016/j.cej.2008.03.011

Armstrong, L. M., Gu, S., \& Luo, K. H. (2010). Study of wall-to-bed heat transfer in a bubbling fluidised bed using the kinetic theory of granular flow. International Journal of Heat and Mass Transfer, 53(21-22), 4949-4959. doi:10.1016/j.ijheatmasstransfer.2010.05.047

Beetstra, R., Hoef, M. Van der, \& Kuipers, J. (2007). Drag force of intermediate Reynolds number flow past mono and bidisperse arrays of spheres. AIChE Journal, 53(2), 489-501. doi:10.1002/aic

De Souza Braun, M. P., Mineto, A. T., Navarro, H. A., Cabezas-Gómez, L., \& da Silva, R. C. (2010). The effect of numerical diffusion and the influence of computational grid over gas-solid two-phase flow in a bubbling fluidized bed. Mathematical and Computer Modelling, 52(9-10), 1390-1402. doi:10.1016/j.mcm.2010.05.017

Deen, N. G., Van Sint Annaland, M., Van der Hoef, M. a., \& Kuipers, J. a. M. (2007). Review of discrete particle modeling of fluidized beds. Chemical Engineering Science, 62(1-2), 28-44. doi:10.1016/j.ces.2006.08.014

Du, W., Bao, X., Xu, J., \& Wei, W. (2006). Computational fluid dynamics (CFD) modeling of spouted bed: Assessment of drag coefficient correlations. Chemical Engineering Science, 61(5), 1401-1420. doi:10.1016/j.ces.2005.08.013

Esmaili, E., \& Mahinpey, N. (2011). Adjustment of drag coefficient correlations in three dimensional CFD simulation of gas-solid bubbling fluidized bed. Advances in Engineering Software, 42(6), 375-386. doi:10.1016/j.advengsoft.2011.03.005

Gidaspow, D. (1994). Multiphase Flow and Fluidization: Continuum and Kinetic Theory Description. San Diego: Academic Press.

Gupta, C. K., \& Sathiyamoorthy, D. (1999). Fluid Bed Technology in Materials Processing. Boca Raton: CRC Press.

Halvorsen, B. (2005). An Experimental and Computational Study of Flow Behaviour in Bubbling Fluidized Beds. The Norwegian University of Science and Technology (NTNU).

Hill, R. J., Koch, D. L., \& Ladd, A. J. C. (2001). Moderate-Reynolds-number flows in ordered and random arrays of spheres. Journal of Fluid Mechanics, 448, 243-278. doi:10.1017/S0022112001005936 
Hoef, M. Van der, Beetstra, R., \& Kuipers, J. (2005). Lattice-Boltzmann simulations of lowReynolds-number flow past mono- and bidisperse arrays of spheres: results for the permeability and drag force. J. Fluid Mech, 528, 233-254. doi:10.1017/S0022112004003295

Hosseini, S. H., Ahmadi, G., Saeedi Razavi, B., \& Zhong, W. (2010). Computational Fluid Dynamic Simulation of Hydrodynamic Behavior in a Two-Dimensional Conical Spouted Bed. Energy \& Fuels, 24(11), 6086-6098. doi:10.1021/ef100612r

Hosseini, S. H., Zhong, W., Esfahany, M. N., Pourjafar, L., \& Azizi, S. (2010). CFD Simulation of the Bubbling and Slugging Gas-Solid Fluidized Beds. Journal of Fluids Engineering, 132(4), 041301. doi:10.1115/1.4001140

Kunii, D., \& Levenspiel, O. (1991). Fluidization Engineering (second ed.). London: Butterworths.

Li, P., Lan, X., Xu, C., Wang, G., Lu, C., \& Gao, J. (2009). Drag models for simulating gas-solid flow in the turbulent fluidization of FCC particles. Particuology, 7(4), 269-277. doi:10.1016/j.partic.2009.03.010

Lim, K., Zhu, J., \& Grace, J. (1995). Hydrodynamics of gas-solid fluidization. International Journal of Multiphase Flow. $\quad$ Retrieved from http://www.sciencedirect.com/science/article/pii/030193229500038Y

Lindborg, Hå., Lysberg, M., \& Jakobsen, H. a. (2007). Practical validation of the two-fluid model applied to dense gas-solid flows in fluidized beds. Chemical Engineering Science, 62(21), 58545869. doi:10.1016/j.ces.2007.06.011

Loha, C., Chattopadhyay, H., \& Chatterjee, P. (2012). Assessment of drag models in simulating bubbling fluidized bed hydrodynamics. Chemical Engineering Science, 75, 400-407. doi:10.1016/j.ces.2012.03.044

Min, J., Drake, J. B., Heindel, T. J., \& Fox, R. O. (2010). Experimental Validation of CFD Simulations of a Lab-Scale Fluidized-Bed Reactor with and Without Side-Gas Injection, 56(6). doi:10.1002/aic

Oka, S., \& Anthony, E. J. (2004). Fluidized Bed Combustion (p. 616).

Ranade, V. (2001). Computational Flow Modeling for Chemical Reactor Engineering: Process Systems Engineering, Volume 5. Chemical Petrochemical Process (pp. 1-480).

Reuge, N., Cadoret, L., Coufort-Saudejaud, C., Pannala, S., Syamlal, M., \& Caussat, B. (2008). Multifluid Eulerian modeling of dense gas-solids fluidized bed hydrodynamics: Influence of the dissipation parameters. Chemical Engineering Science, 63(22), 5540-5551. doi:10.1016/j.ces.2008.07.028 
Sobieski, W. (2009). Momentum exchange in solid-fluid system modeling with the Eulerian multiphase model. Drying Technology, (March 2012), 37-41. doi:10.1080/07373930902827379

Syamlal, M., Rogers, W., \& O’Brien, T. J. (1993). MFIX Documentation: Volume 1, Theory Guide. National Technical Information Service. Springfield.

Taghipour, F., Ellis, N., \& Wong, C. (2005). Experimental and computational study of gas-solid fluidized bed hydrodynamics. Chemical Engineering Science, 60(24), 6857-6867. doi:10.1016/j.ces.2005.05.044

Van der Hoef, M. a., van Sint Annaland, M., Deen, N. G., \& Kuipers, J. a. M. (2008). Numerical Simulation of Dense Gas-Solid Fluidized Beds: A Multiscale Modeling Strategy. Annual Review of Fluid Mechanics, 40(1), 47-70. doi:10.1146/annurev.fluid.40.111406.102130

Van Wachem, B. G. M., Schouten, J. C., van den Bleek, C. M., Krishna, R., \& Sinclair, J. L. (2001). Comparative analysis of CFD models of dense gas-solid systems. AIChE Journal, 47(5), 1035-1051. doi:10.1002/aic.690470510

Vejahati, F., Mahinpey, N., Ellis, N., \& Nikoo, M. B. (2009). CFD simulation of gas-solid bubbling fluidized bed: A new method for adjusting drag law. The Canadian Journal of Chemical Engineering, 87(1), 19-30. doi:10.1002/cjce.20139

Wang, J., \& Liu, Y. (2010). EMMS-based Eulerian simulation on the hydrodynamics of a bubbling fluidized bed with FCC particles. Powder Technology, 197(3), 241-246. doi:10.1016/j.powtec.2009.09.022

Yang, N., Wang, W., Ge, W., \& Li, J. (2003). CFD simulation of concurrent-up gas-solid flow in circulating fluidized beds with structure-dependent drag coefficient. Chemical Engineering Journal, 96(1-3), 71-80. doi:10.1016/j.cej.2003.08.006

Zhang, Y. ., \& Reese, J. M. (2003). The drag force in two-fluid models of gas-solid flows. Chemical Engineering Science, 58(8), 1641-1644.

\section{Acknowledgment}

The authors are grateful to National Council of Technological and Scientific Development (CNPq) process (150894/2014-7). São Paulo Research Foundation (FAPESP) process (2013/21244-5). 